\title{
Online learning technologies as a modern direction of learning in communities
}

\author{
Tatyana Klevetova ${ }^{1 *}$, Svetlana Komissarova ${ }^{2}$, and Konstantin Popov ${ }^{1}$ \\ ${ }^{1}$ Volgograd State Socio-Pedagogical University, Department of Methodology of Teaching \\ Mathematics and Physics, ICT, Volgograd, Russia \\ ${ }^{2}$ Volgograd State Socio-Pedagogical University, Department of Informatics and Methodology of \\ Teaching Informatics, Volgograd, Russia
}

\begin{abstract}
This article discusses the implementation of technologies of online learning in the mode of massive open online courses, namely, online classes, which are considered as a platform for distance learning and interactive communication between students and teacher. These technologies allow to provide the choice of content, rate, forms of work for students, to increase level of individualization and personification of education, to facilitate learning irrespective of place and time of being, to decrease subjectiveness of evaluation of learning results, to make the learning process more accessible. Theoretical foundations of connectivism are considered as a learning theory implementing the learning process on the basis of online information technologies. This approach changes the role of the teacher, who, acting as a tutor, regulates the pace and volume of students' work, organizes the exchange of information, thereby creating a community. This article determines the reasons and features of creation of communities of teachers and students during studying in massive open online course. In the frames of this study, network community is considered as a group of students and teachers participating in interactive communication by means of network tools, social networks and messengers. This communication format allows to solve the problems of formation not only of subject but also of meta-subject results of learning, namely, communicative properties of students. The features of construction of communicative activity in these communities are exemplified by the course titled Preparing students for USE in mathematics (profile level), implemented in Volgograd State SocioPedagogical University on Miroznai platform. Examples of classes are discussed, each being devoted to solution to one of the task types presented in ESU in mathematics of profile level. Analysis of execution of tests proposed in the course demonstrates that the results of the considered students are somewhat higher than those of students studying in isolation.
\end{abstract}

Keywords: online learning, distance course, massive open online course, network educational community.

* Corresponding author: sa.k73@bk.ru 


\section{Introduction}

The modern stage of education development is related with implementation of online learning technologies at all stages. These technologies allow to organize distance learning by online interaction between communities of students and teachers, which, in its turn, provides variety of ways to obtain education, mobility of subjects of the educational process, allowing to organize their interaction in a new way.

This work is aimed at analysis of distance learning as a method of creation of students' community and implementation of learning process on the basis of subject online classes.

\section{Methods}

The research methods were comprised of analysis of pedagogical and methodological publications on organization of online distance learning in communities.

According to S.V. Gerkushenko (Sokolova), G.G. Gerkushenko, M.V. Sokolov, A.A. Filimonov [1,2], community is analyzed from two points of view, namely: community of teachers performing teaching activity aimed at achievement of results stipulated by FSES, and community of students studying online and mastering the content of academic disciplines. Studying in communities is based on online distance technologies, which provide the required content of studied material to students by interactive communication between students and teachers, as well as opportunity of independent activity on mastering the required material.

A.A. Beloglazov, L.B. Beloglazova, O.V. Kozelkov, E.V Pinevich, Zh.V. Smirnova, Zh.V. Chaykina [3-6] mention that the distance form of learning is a modern educational system of the new millennium, it is efficient at any stage of studying, since it provides wider interaction and obtaining of new information by means of multimedia.

M.B. Lebedeva [7] reports that the distance learning as an interactive method is the most promising upon implementation of online learning and massive open online courses. Some Russian and foreign researchers [7-11] consider massive open online courses as the courses with interactive participation and open access for unlimited number of trainees.

The use of distance learning technologies in the form of massive open online courses allows to provide the choice of content for students [12]. It means that students can independently select the rate of course presentation, select the form of work and even determine partially the studied content, which should be obtained during studying the materials proposed by the course authors. Such approach provides a new level of principles of individualization and personification of learning. As a feature of online courses, it is possible to highlight opportunity to study irrespective of time, place and involved equipment.

All this led to the emergence of a new theory of learning $[13,14]$ known as connectivism, which attempted to substantiate the opportunities provided by availability of modern information and communication technologies, potentials and speed of online services: starting from e-mail to blogs and YouTube.

A key feature of the connectivism is that major portion of learning process can be transferred to the Internet. In terms of connectivism, the role of teacher is reduced to adjusting information flows, into which the students are plunged, with necessity to answer key questions. Respectively, the teacher helps the students to study and to share information among themselves. The students should independently search for information in Internet and present the acquired material for common discussion. Therefore, the acquired information becomes a center of community. 


\section{Results}

This research is based on the massive open online course titled Preparing students for USE in mathematics (profile level), implemented in Volgograd State Socio-Pedagogical University. In 2018-2019 academic year, it was attended by more than one thousand pupils and about one hundred teachers. This course was deployed at Miroznai platform based on Open edX environment jointly developed by experts from Harvard and Massachusetts Institute of Technology.

The course "Preparing students for USE in mathematics (profile level)" was initially developed in two variants: preparing students for USE and advanced training of teachers. Under the common title, the course was implemented in 2019-2020 academic year. Respectively, the course is comprised of variants of independent studying of material by students, and of studying under the guidance and control by teacher.

Each session of this distance course corresponds to a task of USE (Unified State Examination) in mathematics of profile level with subdivision of the session into categories.

The number of categories varies depending on the task type. For instance, a task in probability is characterized by the following categories:

- classical equation of probability;

- opposite events;

- coin;

- dices;

- addition of probabilities;

- value range;

- multiplication of probabilities;

- complete and incomplete tree;

- random walk;

- Bernoulli equation;

- Euler diagram and probability;

- mathematical expectancy.

Each category is comprised of analysis of preliminary tasks and a set of tasks with opportunity to use hints for complete comprehension of solving sequence when the task cannot be solved (Fig. 1).
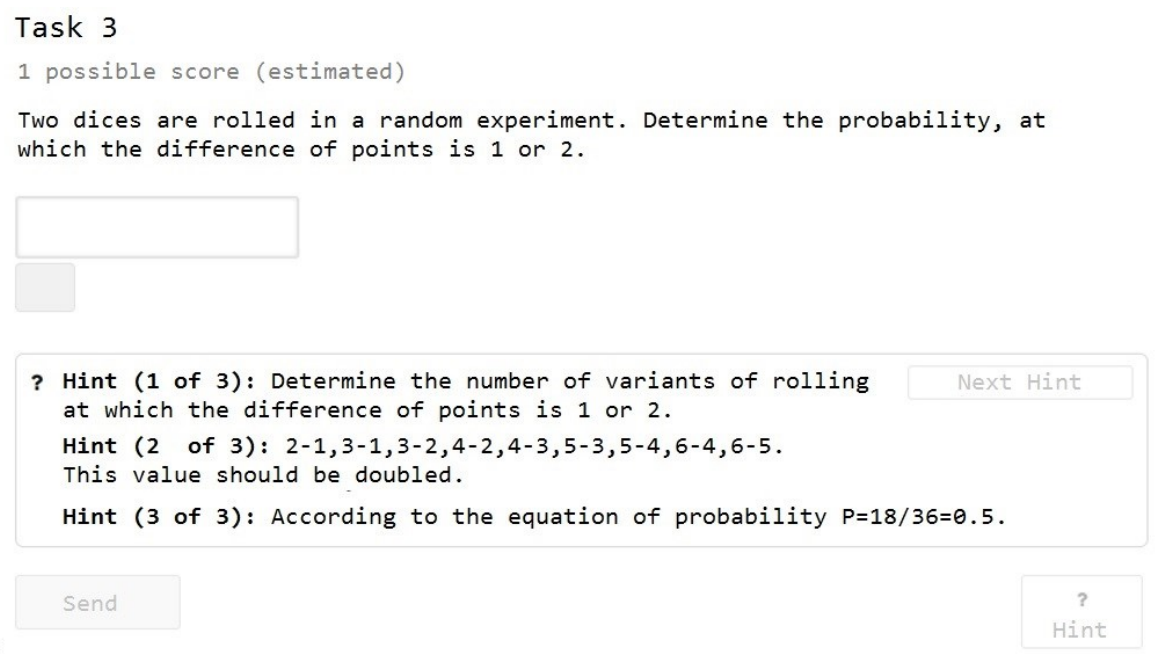

Fig. 1. Task with a system of hints. 
Even such system of hints does not eliminate the demand of students to communicate and to address questions either to a teacher or to other students. In particular, regarding the aforementioned task, the following questions were asked:

1. How to determine the number of rolling variants, upon which the difference of points is 1 or 2 ?

2. What for do we double the variants given in the hint?

3. Why do we divide by 36 in the equation of probability?

Quite often the students ask such questions, which seem to be not requiring answer from the point of view of a teacher (or author of the course, "irrelevant"), but the answers to these questions are quite meaningful for the students.

There are numerous technologies to implement trainees' communication, both of students and teachers. The distance course itself proposes communication in embedded chat. However, the experience has demonstrated that this chat is mainly used for addressing the course organizers to clarify these or those issues regarding technical part of learning. More rarely it is used to explain solution of difficult tasks, when not all tasks are equipped by hints (each assignment is accompanied by final test).

Communication mostly takes place in social networks and messengers. Exactly due to the latter, the firmest and long-term links are formed in the communities of both the teachers, who use the communication to solve their professional tasks, and the students developing their communicative properties related to meta-subject results of learning process according to valid FSES [15].

Respectively, the students of secondary school should learn to acquire, to highlight, and to qualitatively analyze the information, which is mostly available due to the Internet. For instance, the Internet contains reference materials and numerous original sources, which students should know. Therefore, the students' question "Where did you find?" becomes one of the most urgent components of communicative activity of modern students.

Therefore, communication of students in the frames of the considered distance course is as fully as possible within the framework of formation of these skills. Communication of students in the frames of execution of assignments, proposed for solution in the distance learning course, can transfer the communicative skills of the students to qualitatively new level. The students should express not only emotional coloring of emerging problematic situation (emotions are usually shown by interjections or emoticons) but even upon formulation of survey, they face the necessity to use information intensive phrases, word combinations in written speech. And solution of more complex tasks requires for application of respective scientific terminology.

Nearly all aforementioned features of communication in students' community are peculiar in similar community of teachers, emerging around teachers' work with regard to students' activity in the frames of studying in the online course.

A question arises: how to evaluate the efficiency of working in community upon execution of assignments of massive open online course?

Activity in teachers' community becomes obvious during check of final assignments executed by some of its members. The fact is that during passing the course the teachers should write an essay on a suggested topic. The essays proposed for evaluation are sometimes similar in content and characterized by peculiar features of text arrangement, which suggests the idea of trainees' communication.

It is more difficult to reveal the influence of communication in community on results of students' learning. First of all, the evaluation system in the course "Preparing students for USE in mathematics" is comprised of tests including tasks from 1 to 12 . Herewith, execution of tests is obligatory to pass to next section. Such next section becomes available in the case of successful execution of at least $70 \%$ of tasks. Thus, for detection of features there is a clearance of $30 \%$, which is not too high. 
Another issue is related with the fact that some tasks of USE in mathematics, even according to official statistics of Federal Institute of Pedagogical Measurements (FIPM), have solvability close to 100 in the examinations. Analysis of test solution in these topics could not be informative in the context that is needed.

Therefore, for the analysis, tasks 7, 8, 11, and 12 were selected. Tasks 7 and 12 are devoted to derivative, task 8 - to stereometry, and task 11 is text. Percentage of solving these tasks according to FIPM varies from 60 to 70 .

The experimental group was comprised of the students ( 52 persons) recorded by teachers ( 6 teachers recorded groups of 7 - 11 persons), i.e., they a-priori knew each other before they took the course and, respectively, communicated actively among themselves. The reference group was comprised of randomly selected students, who were recorded by themselves.

The analysis has demonstrated that in the reference group, the portion of solved tests varied from 73 to 79 , whereas in the experimental group, this portion comprised of different tasks was from 84 to 93 .

\section{Conclusion}

Massive open online courses become a portion of general education system, which is dictated by a set of factors starting from rapid development of technological base and ending with the developed pandemic. Therefore, they act during studying activity as centers of communities of students and teachers. Herewith, communication in the mentioned communities leads to development of both communicative skills based on the appropriate communicative online technologies and skills of solving tasks in distantly studied disciplines.

\section{Acknowledgments}

This work was supported by the Russian Foundation for Basic Research, project No. 19-29-14064: Theoretical and methodological foundations and engineering provision of educational activity in online communities of school students.

\section{References}

1. S.V. Gerkushenko (Sokolova), G.G. Gerkushenko, M.V. Sokolov, Concept, 11, 146150 (2014)

2. A.A. Filimonov, Gumanitarnyye issledovaniya, 1(14), 98-105 (2017)

3. A.A. Beloglazov, L.B. Beloglazova, Bulletin of the Peoples' Friendship University of Russia. Series Informatization of Education, 14(1), 83-91 (2017)

4. O.V. Kozelkov, Actual problems of the humanities and natural sciences, 3(1), 91-93 (2017)

5. Ye.V. Pinevich, International scientific journal, 6, 106-110 (2017)

6. Zh.V. Smirnova, Zh.V. Chaykina, World of Sciences, 5(2), 1-7 (2017)

7. M.B. Lebedeva, Chelovek i obrazovaniye, 1(42), 105-108 (2015)

8. S. Downes, The rise of MOOCs (April 23, 2012). Accessed on: September 30, 2020. [Online]. Available: http://www.downes.ca/post/57911

9. H.M. Dai, T. Teo, N.A. Rappa, Computers in Human Behavior, 112, 106455 (2020). https://doi.org/10.1016/j.chb.2020.106455

10. Y. Jung, J. Lee, Computers and Education, 122, 9-22 (2018). https://doi.org/10.1016/j.compedu.2018.02.013 
11. N.L. Romanova, Higher education pedagogy, 2(12), 5-8 (2018)

12. A.A. Andreyev, V.I. Soldatkin, Distance learning: essence, technology, organization (MESI publishing house, Moscow, 1999)

13. G. Siemens, International Journal of Instructional Technology \& Distance Learning, 2(1), 3-10 (2005)

14. S. Downes, Journal of Emerging Technologies in Web Intelligence, 2(1), 27-33 (2010)

15. Order of the Ministry of Science and Higher Education of the Russian Federation "On the Approval and Introduction of the Federal State Educational Standard Secondary General Education" No. 413 dated October 6, 2009 (as amended by Order of the Ministry of Education and Science of Russia No. 1645 dated December 29, 2014). Accessed on: September 28, 2020. [Online]. Available:

https://gos.ru/LMS/wm/wm_fgos.php?id=sred 